\title{
Catalytic Removal of NOx by Cerium-Modified Zirconium Composite Oxide
}

\author{
Nailv Guo \\ Shanghai Maritime University, Shanghai, China \\ Email: 275858072@qq.com
}

How to cite this paper: Guo, N. L. (2019). Catalytic Removal of NOx by CeriumModified Zirconium Composite Oxide. Journal of Geoscience and Environment Protection, 7, 66-82. https://doi.org/10.4236/gep.2019.76006

Received: May 5, 2019

Accepted: June 22, 2019

Published: June 25, 2019

Copyright $\odot 2019$ by author(s) and Scientific Research Publishing Inc. This work is licensed under the Creative Commons Attribution International License (CC BY 4.0).

http://creativecommons.org/licenses/by/4.0/ (c) (i) Open Access

\begin{abstract}
Diesel engines have been widely used due to their high thermal efficiency, good environmental adaptability, wide power adjustment range, convenient maintenance and long service life. However, the application of diesel engines is also facing a serious problem; that is, the emission of nitrogen oxides and particulate matter is serious. For marine diesel engine emission requirements, MARPOL Convention Annex VI imposes strict restrictions on the emission of atmospheric pollutants. The limit emission of nitrogen oxides in the Tier III emission standards mandated by IMO is $3.4 \mathrm{~g} / \mathrm{kWh}$. Therefore, in order to meet the requirements of international conventions and countries and regions, it is necessary to control the emissions of diesel engines. The NOx in the exhaust gas is mostly a thermal type of nitrogen oxide which is produced under high temperature and high pressure conditions formed during compression and combustion strokes. The diesel engine relies on the compression energy of the mixture to ignite, and the good injection atomization effect is not achieved. The distribution of the detonation point is not uniform, and local high temperature points are generated in some areas, which increases the NOx formation. The main means of reducing NOx emissions are organic internal control and post-treatment. However, the use of internal control technology to reduce the internal temperature of the machine will deteriorate the fuel combustion conditions, so that the fuel cannot be completely burned, and the emissions of incomplete combustion products such as PM and CO increase. It is difficult to achieve NOx reduction by simply relying on the internal control technology, so it is necessary to use post-processing technology. The combined use of different emission reduction technologies is also a hot topic in emissions control research. The post-treatment methods for NOx emission reduction include direct catalytic decomposition, selective non-catalytic reduction, selective catalytic reduction, lean-burn adsorption catalytic reduction, and low-temperature plasma assisted technology. The current research and application schemes in the industry are SCR selectivity. Catalytic reduction and
\end{abstract}


LNT lean combustion adsorption reduction. In this paper, the partial replacement of Ce by La is carried out to modify the Ce/ $\mathrm{Zr}$ composite oxide. The mass fraction of $\mathrm{La}_{2} \mathrm{O}_{3}$ in the prepared $\mathrm{La} / \mathrm{Ce} / \mathrm{Zr}$ composite oxide was $5 \%$, and the physicochemical properties of $\mathrm{La} / \mathrm{Ce} / \mathrm{Zr}$ composite oxide powder were analyzed by ICP, OSC, SEM and TPR techniques. The experiment found that: 1) La can refine the grain and inhibit the grain growth, so that the powder obtains a higher specific surface area and a smaller particle size distribution. 2) The addition of La reduces the sintering of cerium-zirconium and improves the heat aging resistance of the catalyst under the inhibition of high temperature. 3) After doping La, it enhances the migration of surface lattice oxygen and enhances the oxygen storage capacity; the addition of La enhances the NO adsorption capacity of cerium-zirconium and improves the catalytic activity of the catalyst. The light-off temperature and the highest activity temperature of PM decrease, and the reduction rate of No is $19.2 \%$.

\section{Keywords}

Composite Oxide, Rare Earth, Tail Gas Treatment, Catalyst, NOx

\section{Introduction}

With the passage of time, especially the initiation of the industrial revolution, human development has undergone earth-shaking changes in all aspects of human life. At the same time, it has also caused tremendous damage to the environment. In addition to the frequent occurrence of various natural disasters around the world in recent years, people's awareness of environmental protection has gradually strengthened. In the process of development, the birth of various means of transportation brings convenience to people, such as airplanes, cars, ships and so on. As a power machine, internal combustion engines are widely used in power plants of various vehicles due to their high utilization of thermal energy. High dynamical and economical performances of the diesel engine make it develop rapidly at home and abroad. In Europe, the proportion of diesel engines used in cars and commercial vehicles is $20 \%$ and $90 \%$ respectively, while that in Japan is also $9.2 \%$ and $38 \%$. Some parts of the United States use diesel engines (Gao et al., 2001). Although China's development is relatively late, its development is very rapid. The main pollutants in diesel exhaust emissions include particulate matter (PM), nitrogen oxides (NOx), hydrocarbons (HC) and carbon monoxide (CO).

Modern diesel engines generally use a large air-fuel ratio, and the exhaust gas is in an oxygen-rich environment. The oxides emission requirements are quite strict, and there are also reducing components such as CO and PM in the diesel exhaust. These two kinds of pollutants can be removed simultaneously by the reduction reaction of NOx and these reductive components in dilute gas atmosphere and the addition of appropriate catalysts. This multi-effect catalytic tech- 
nology under lean-burn conditions (Dong \& Shuai, 2007) is a highly practical exhaust gas treatment technology. The active components used as the catalyst include noble metal, base metal oxides such as alkali metals, alkaline earth metals, transition metals and rare-earth metals, perovskites and perovskite-like and spinel-type composite oxides, and so on.

Most of the diesel engine operating conditions is in lean-burn conditions, and the three-way catalytic converter of the gasoline engine cannot meet the NOx and PM emission control of the diesel engine under lean oxygen-rich environment. In order to properly control the incomplete combustion products $\mathrm{CO}$ and particulate matter PM and high temperature product NOx emissions in diesel exhaust, the current research progress is mostly combined with a variety of catalytic conversion technologies (Zhang et al., 2008). For example, the adsorption reduction catalyst LNT is combined with a PM particle trap DPF, and then used in series with an oxidation catalytic converter DOC, a PM particle trap DPF in combination with a selective catalytic reduction catalyst, and the like. The multi-catalytic conversion technology has been applied in practice and applied to small diesel engines with good results.

Toyota has introduced a DPNR (Diesel Particulate-NOx Reduction systems) that simultaneously catalyzes the removal of PM and NOx from diesel engines (Tsyganok et al., 2004). The main components of the purification device are a storage reduction NSR catalyst and a dense pore ceramic particle trap DPF. The ceramic trap DPF acts as a coating carrier for the NOx storage reduction catalyst and is capable of trapping carbon particulates in the flue gas. Yoshida (Yoshida et al., 2006) proposed the concept of reducing nitrogen oxides by using soot particles trapped in a trap under an oxygen-rich atmosphere. PM acts as a reducing agent and NOx acts as an oxidant. Both undergo oxidation-reduction reactions in an oxygen-rich atmosphere. Nitrogen and $\mathrm{CO}_{2}$, and experimentally studied and explored the possibility of redox reaction between the two. Since this treatment technology does not require the use of an additional reducing agent, the management is also convenient and the cost is low, so this is also an ideal diesel exhaust after treatment technology. It has been found that under certain catalysis, the reaction temperature range of PM oxidation and NOx reduction will overlap to a large extent, which is basically in the same reaction temperature range. Under the oxidation of NOx, PM can be reduced to some extent. The activation energy of oxidation promotes the low temperature combustion of PM, so simultaneous catalyzed removal of NOx and soot particles on the same catalytic bed is achievable (Xu et al., 2009). This puts forward requirements for the research of catalysts, and it is also one of the research hotspots of diesel engine emission reduction control.

At present, more research is based on the partial or complete replacement of precious metal catalysts with perovskite-type composite oxides ( $\mathrm{Li}$ et al., 2006). For the perovskite-type $\mathrm{ABO}_{3}$ composite oxide, the A-site ion can be replaced with an alkali metal or a rare earth metal, and the B-site cation can be infiltrated 
by the transition metal or the noble metal. The $\mathrm{ABO}_{3}$ composite oxide has excellent performance in removing and the NOx and the PM. Substituting B-site ions with transition metals such as $\mathrm{Ni}$ and $\mathrm{Mn}$, among which $\mathrm{LaNi}_{0.5} \mathrm{Mn}_{0.5} \mathrm{O}_{2}$ and $\mathrm{LaMg}_{0.33} \mathrm{Mn}_{0.67} \mathrm{O}_{2}$ have strong oxidizing power, and the ability to oxidize $\mathrm{CO}$ is even higher than Pt. Rare earth and transition metals were used to replace $\mathrm{A}$ and $\mathrm{B}$ ions, respectively. Among them, $\mathrm{La}_{0.4} \mathrm{Sr}_{0.6} \mathrm{Co}_{0.8} \mathrm{Mn}_{0.2} \mathrm{O}_{2}$ showed high reduction activity for NOx, and the reduction efficiency reached $86.4 \%$. Both cerium (Ce)/zirconium $(\mathrm{Zr})$ are metamorphic metals and can be converted between +3 and +4 , thus having a strong oxidizing power. The cerium-zirconium composite has strong adsorption capacity, high surface activity and good dispersion, which is beneficial to the oxidation of PM and CO and the reduction of NOx. This paper mainly discusses the modification of cerium-zirconium composites by replacing some of the Ce ions with rare earth metal La, and demonstrates the excellent physicochemical properties of $\mathrm{Ce} / \mathrm{Zr}$ composites, including specific surface area, hydrothermal stability, and oxygen storage capacity and so on.

\section{Experimental Part}

\subsection{Preparation of Catalytic Powder}

During the preparation of the catalyst powder, different parameters such as solution concentration, $\mathrm{PH}$ value, precursor and burning temperature and reaction time will affect the expression of the physicochemical properties of the catalyst, such as specific surface area, catalytic performance, etc. In this experiment, rare earth nitrate was used as rare earth source, ammonium bicarbonate as precipitator and cetyltrimethylammonium bromide as surface active dispersant to prepare catalyst powder (Wang \& Shi, 2006) (Wang et al., 2008).

The ratio of the mass fraction of each component in the desired powder material is $\left(\mathrm{La}_{2} \mathrm{O}_{3}\right):\left(\mathrm{CeO}_{2}\right):\left(\mathrm{ZrO}_{2}\right)=5: 65: 30$, and the desired masses of $\mathrm{La}\left(\mathrm{NO}_{3}\right)_{3} \cdot 6 \mathrm{H}_{2} \mathrm{O}$, $\left.\mathrm{Ce}\left(\mathrm{NO}_{3}\right)_{3} \cdot 6 \mathrm{H}_{2} \mathrm{O}, \mathrm{Zr}\left(\mathrm{NO}_{3}\right)_{4} \cdot 5 \mathrm{H}_{2} \mathrm{O}\right), \mathrm{NH}_{4} \mathrm{HCO}_{3}$ and cetyltrimethylammonium bromide are calculated and weighed;, dissolving rare earth nitrate and cetyltrimethylammonium bromide in deionized water, and the total concentration of rare earth ions is $0.5 \mathrm{~mol} / \mathrm{L}$. Ammonium hydrogencarbonate was dissolved in deionized water at a concentration of $1 \mathrm{~mol} / \mathrm{L}$. Both solutions were stirred at room temperature to allow for complete dissolution. The $\mathrm{PH}$ of the $\mathrm{NH}_{4} \mathrm{HCO}_{3}$ solution was adjusted to about 8.5 with ammonia water. Using a thermostatic magnetic stirrer slowly dilute the ammonium bicarbonate solution into the rare earth ion solution at a constant temperature of $70^{\circ} \mathrm{C}$, and continue magnetic stirring, titration excess, and the $\mathrm{pH}$ is controlled between 8 - 8.5. After constant stirring for a period of time, the precipitate was filtered, washing twice with deionized water, again with absolute ethanol, then dried at $100^{\circ} \mathrm{C}$ for 1 hour, and then placed in a high temperature electric resistance furnace at $800^{\circ} \mathrm{C}$ for 4 hours. A $\mathrm{La} / \mathrm{Ce} / \mathrm{Zr}$ composite oxide powder was obtained, and the catalyst was represented by $\mathrm{La}_{0.05} \mathrm{Ce}_{0.65} \mathrm{Zr}_{0.3} \mathrm{O}_{2}$. 


\subsection{Adsorption Experiment of La/Ce/Zr Composite Powder}

In the heterogeneous catalytic reaction (Wang et al., 2008), the adsorption of the reactants on the surface of the catalyst occurs at the beginning of the reaction, and the formed adsorbed species are the beginning of catalytic activation. Therefore, the catalyst has a strong adsorption property of the reactants, and has a positive effect on promoting the progress of the catalytic reaction.

The temperature programmed reactor can be used as the adsorption platform; the appropriate amount of catalyst powder is fully ground, and $24 \mathrm{ml}$ of the catalyst in a loosely stacked state are taken by the measuring cylinder, and the measured catalyst is uniformly laid on the stainless steel plate, and the temperature rise reaction is put into the temperature programmed reaction chamber. In the cavity, scavenge with $360 \mathrm{~L} / \mathrm{h}$ of helium, program temperature control heating (constant temperature rate of $10^{\circ} \mathrm{C} / \mathrm{min}$ ) to $400^{\circ} \mathrm{C}$, continue to $400^{\circ} \mathrm{C}$ for 1 h, cool down to $200^{\circ} \mathrm{C}$, change $1000 \mathrm{ppm}$ of $\mathrm{NO}$, and the rest is $\mathrm{He}$ equilibrium adsorption standard gas, flow rate of $6 \mathrm{~L} / \mathrm{min}$, program heating (temperature change rate of $10^{\circ} \mathrm{C} / \mathrm{min}$ ) to $550^{\circ} \mathrm{C}$, measuring $\mathrm{NO}$ concentration per minute.

\subsection{Oxygen Storage Performance Test}

Oxygen storage capacity is an important indicator to measure the catalytic ability of cerium-zirconium composites. Its role and significance have been described in the previous section. The specific testing process is as follows.

Weigh $5 \mathrm{~g}$ of catalyst powder; use a volume fraction of $10 \% \mathrm{O}_{2}$ (helium gas balance) at $400^{\circ} \mathrm{C}$ for 2 hours; switch to He atmosphere for cooling to room temperature; use the volume of $15 \% \mathrm{CO}$ (the balance is He balance) to supply air; the temperature is continuously raised to $400^{\circ} \mathrm{C}$; when the $\mathrm{CO}$ content is restored to the baseline, after the $\mathrm{CO}_{2}$ generation, the gas is switched to He, the temperature is lowered to $200^{\circ} \mathrm{C}$; in that temperature, the volume fraction of $10 \% \mathrm{O}_{2}$ (the balance is He balance) continues to supply gas until the $\mathrm{O}_{2}$ content returns to the baseline level, that is, to the adsorption saturation state; the $\mathrm{O}_{2}$ concentration is detected in the adsorption process; the $\mathrm{O}_{2}$ adsorption curve is plotted, and the $\mathrm{O}_{2}$ adsorption amount is integrated to obtain the corresponding OSC value.

\subsection{Heat Aging Experiment}

In some cases, the exhaust temperature of the diesel engine will increase, such as secondary combustion, soot combustion, etc. At this time, the temperature will reach $800^{\circ} \mathrm{C}$, or even $1000^{\circ} \mathrm{C}$. Many metal oxides will be sintered in high temperature environment, the original structure and properties will be lost, pure $\mathrm{CeO}_{2}$ is less stable, $850^{\circ} \mathrm{C}$ sintering, cerium zirconium composite has good heat aging resistance, can be in $1000^{\circ} \mathrm{C}$ environment Use underneath while maintaining a large oxygen storage capacity. The heat aging test is to test the effect of La doping on the heat aging resistance of the catalyst.

The experimental process is: After appropriate amount of the catalyst powder 
is thoroughly ground, placed in a high-temperature resistance furnace, heated to $1000^{\circ} \mathrm{C}$ at a certain temperature rise rate in an air atmosphere kept for $4 \mathrm{~h}$, and stopped heating and then slowly cooled to room temperature. Then determine the specific surface area and OSC value of the catalyst subjected to heat aging test to test its heat aging resistance.

\subsection{Catalytic Performance Evaluation Test}

Using a temperature-controlled heater as a catalytic reaction platform, the experiment used a small space velocity of $2000 \mathrm{~h}^{-1}$, using a measuring cylinder to measure the $3.6 \mathrm{ml}$ of the catalyst powder in the stacked state, and mixing and grinding according to the catalyst to PM mass ratio of 1:1. The mixed particles were evenly spread on a stainless steel plate and placed in a temperature controlled heater chamber. The chamber was purged with helium at a flow rate of $360 \mathrm{~L} / \mathrm{h}$ and heated to $400^{\circ} \mathrm{C}$ (temperature rise rate $10^{\circ} \mathrm{C} / \mathrm{min}$ ), maintained heated for $0.5 \mathrm{~h}$, then cooled to $200^{\circ} \mathrm{C}$, and the reaction was $360 \mathrm{~L} / \mathrm{h}$ Standard gas, continue to heat up to $700^{\circ} \mathrm{C}$ (temperature rise rate $10^{\circ} \mathrm{C} / \mathrm{min}$ ), measured $\mathrm{NO}, \mathrm{NO}_{2}$ and $\mathrm{CO}_{2}$ concentration per minute.

\subsection{Characterization of Catalyst Physicochemical Properties}

The prepared powders were characterized by specific surface model ASAP2100, laser particle size model Coulter LS-230, ICP, SEM model JSM-7500F and other characterization techniques.

\section{Test Results and Analysis}

\subsection{ICP Analysis}

Table 1 shows the results of ICP detection of the yttrium-zirconium complex, and the content of the phase element in the ICP, that is, the chemical composition and corresponding content of the composite as a whole. It can be seen from the test results that the La content and the expected design value deviate by $6.4 \%$, while the deviation between $\mathrm{Ce} / \mathrm{Zr}$ and the expected design content is small, and the deviation is about $1 \%$. In addition to cerium zirconium, the whole content also contains $0.06 \%$ of other elements. In ICP results it is shown that the composite contains $\mathrm{Fe}, \mathrm{Si}$ and $\mathrm{Ca}$ impurity elements (a small amount, not listed). These impurities may come from impurities in each rare earth nitrate, so the purity of the raw materials and the separation method of the experimental process have a

Table 1. Quantitative analysis table of chemical composition.

\begin{tabular}{ccc}
\hline Chemical components & Detection content $\%$ & Error\% \\
\hline $\mathrm{La}_{2} \mathrm{O}_{3}$ & 4.68 & -6.4 \\
$\mathrm{CeO}_{2}$ & 65.67 & 1 \\
$\mathrm{ZrO}_{2}$ & 29.59 & -1.4 \\
Total amount of cerium & 99.94 & -0.06 \\
\hline
\end{tabular}


great influence on the preparation of the catalyst. Since the impurity content and the actual content of cerium-zirconium are small, and the actual content ratio of cerium-zirconium is close to the theoretical design of 5:65:30, the obtained catalyst powder can basically meet the experimental requirements and can be designed according to the quality. The catalyst for the stoichiometric ratio is $\mathrm{La}_{0.05} \mathrm{Ce}_{0.65} \mathrm{Zr}_{0.3} \mathrm{O}_{2}$, hereinafter referred to as LCZ.

\subsection{XRD Spectroscopy}

The angles (Figure 1) of the selected diffraction peaks are $2 \theta=29.1485,33.6500$, $48.4818,57.2929,70.4956,77.9706$. The phase of LCZ is mainly composed of the composite phase of $\mathrm{Ce} / \mathrm{Zr}$, which is mainly the diffraction peak of cubic crystal phase $\mathrm{Ce}_{0.6} \mathrm{Zr}_{0.4} \mathrm{O}_{2}$; some $\mathrm{La}$, Ce and $\mathrm{Zr}$ exist in the form of single phase oxide; in $2 \theta=28.587,33.128$, a higher intensity $\mathrm{La}_{2} \mathrm{Zr}_{2} \mathrm{O}_{7}$ diffraction peaks were detected, and the LaZrO composite phase types were more. Other types of LaZrO composite phases were detected at $2 \theta=28.571,33.109$, etc.; since the $\mathrm{LaCeO}$ or LaCe$\mathrm{ZrO}$ composite phase PDF samples were not found, there were no explain this composite phase.

The atomic radii of $\mathrm{La}$ are larger than $\mathrm{Ce} / \mathrm{Zr}$, so structural defects will occur in the formed composite phase. XRD results show that the addition of La increases the type of composite phase and facilitates the formation of defective composite phase, which can increase the surface formation of the catalyst Oxygen vacancy.

\subsection{BET and SEM Specific Surface Area and Particle Size}

The specific surface area can be used to characterize the state in which the catalyst powder can be in contact with the outside. The multiphase reaction belongs

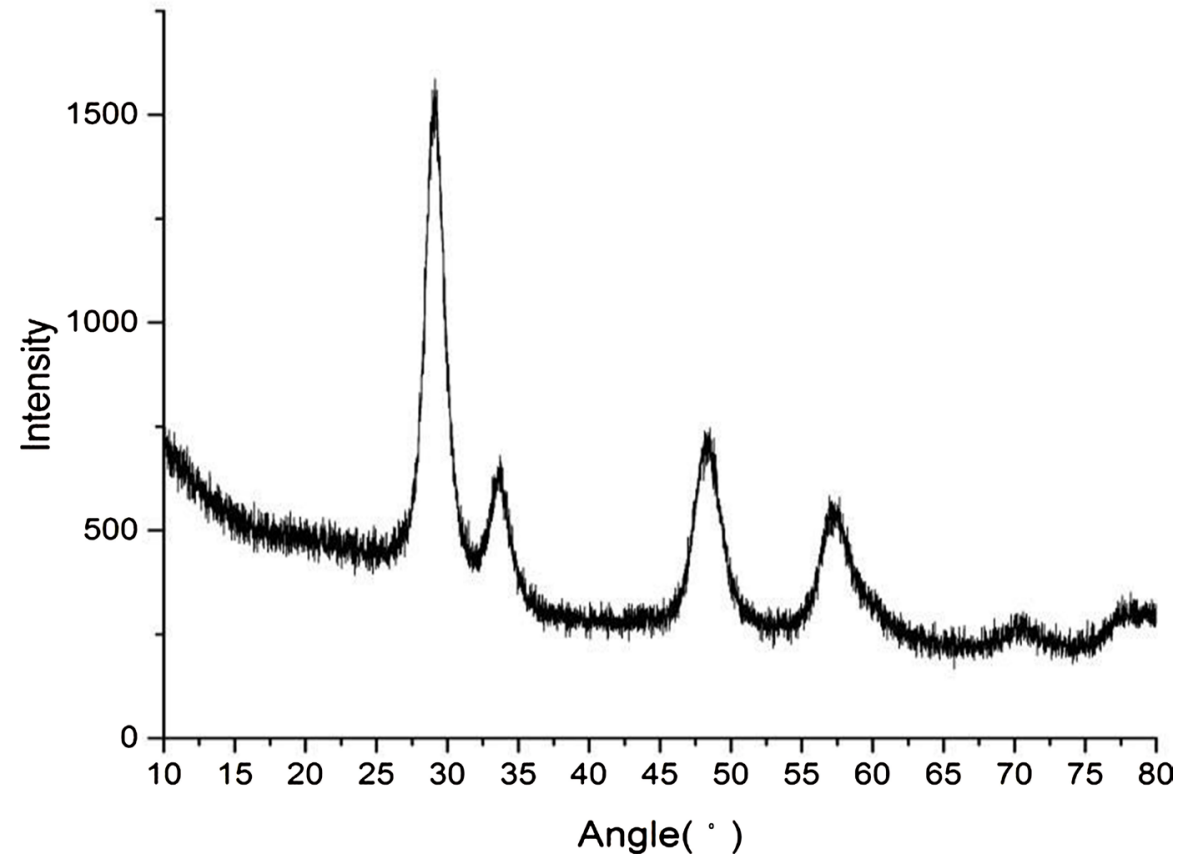

Figure 1. XRD diffraction spectrum. 
to the surface reaction, and the active component distributed on the surface can serve as the active center. The chemical adsorption and redox reactions in the reaction process occur in the surface of the powder. A large specific surface area can improve the contact state with each reactant and improve the adsorption and catalytic ability of the catalyst. The particle size and specific surface area of the pure cerium-zirconium composite and the cerium-zirconium composite were measured using a laser particle size analyzer and a specific surface meter. Through data comparison, it can be found that under the premise of other preparation conditions, after replacing the $\mathrm{Ce}$ with $\mathrm{La}$, the particle size of each particle is significantly reduced, especially the average particle size D50 of the overall particle size level, and the powder of La is added. The D50 was $2.96 \mu \mathrm{m}$, which was $26.6 \%$ lower than that of the pure Ce/Zr composite, and the specific surface area increased significantly, increasing by $32.4 \%$. The above data indicates that after adding $5 \%$ of La, the catalyst crystals are refined during the formation process, and the crystals do not grow continuously (Table 2). It may be that La improves the agglomeration and inhibits the growth of crystals; the specific surface area of the powder is $67.37 \mathrm{~m}^{2} / \mathrm{g}$, which is $32.4 \%$ higher than that of the pure $\mathrm{Ce} / \mathrm{Zr}$ composite. In general, the external surface area of the particles is inversely proportional to the particle size, and the degree of particle size reduction is significantly lower than that of the specific surface area. This indicates that the growth rate of the surface area of the pores of the particles is higher than the growth rate of the external surface area, so that the porosity is increased, and the sintering condition of the surface of the catalyst powder is effectively suppressed and the formation and development of the pore structure are facilitated. Therefore, La helps to refine crystals, inhibit agglomeration and sintering at high temperatures, and obtain a large specific surface area and porosity for the prepared powder.

It can be seen from Figure 2(a) that the particle size distribution in the fresh state is not very uniform, and the small size and large size particles coexist, indicating that the crystal growth process is not very uniform, the overall crystal size is fine, but a small amount of sintering phenomenon appears in the roasting stage; in Figure 2(b), each crystal grows, and there is obvious agglomeration of sintering agglomeration, but some small-sized particles still exist, indicating that the crystal growth in this region is slow. It may be that the distribution of $\mathrm{La}$ is not uniform; resulting in inconsistent crystal growth rates in different regions,

Table 2. Particle size distribution and specific surface area of fresh state before and after la modification.

\begin{tabular}{|c|c|c|c|c|c|c|}
\hline $\begin{array}{r}\begin{array}{r}\text { Particle size } \\
\text { Specific surface } \\
\text { area }\end{array}\end{array}$ & $\begin{array}{l}\mathrm{D} 10 \\
(\mu \mathrm{m})\end{array}$ & $\begin{array}{l}\text { D50 } \\
(\mu \mathrm{m})\end{array}$ & $\begin{array}{l}\mathrm{D} 90 \\
(\mu \mathrm{m})\end{array}$ & $\begin{array}{l}\text { Average crystal } \\
\text { reduced diameter } \\
\text { rate } \%\end{array}$ & $\begin{array}{c}\text { Specific } \\
\text { surface area } \\
\mathrm{m}^{2} / \mathrm{g}\end{array}$ & $\begin{array}{l}\text { Specific } \\
\text { surface } \\
\text { ratio\% }\end{array}$ \\
\hline $\mathrm{Ce}_{0.7} \mathrm{Zr}_{0.3} \mathrm{O}_{2}$ & 1.28 & 4.03 & 8.71 & 0 & 50.89 & 0 \\
\hline $\mathrm{La}_{0.05} \mathrm{Ce}_{0.68} \mathrm{Zr}_{0.3} \mathrm{O}_{2}$ & 0.91 & 2.96 & 6.43 & 26.6 & 67.37 & 32.4 \\
\hline
\end{tabular}


indicating that $\mathrm{La}$ can indeed refine crystals after infiltration and prevent crystal growth and sintering.

\subsection{Oxygen Storage}

The oxygen storage of cerium-zirconium composites is to absorb oxygen into oxygen ions when the valence state of the valence ion is changed to a high valence state. By Table 3, its oxygen storage capacity mainly lies in the price change of $\mathrm{Ce} / \mathrm{Zr}$, from +3 to +4 . The oxygen is stored and the gaseous oxygen is converted into oxygen atoms in the crystal lattice. Therefore, the oxygen storage capacity of the $\mathrm{Ce} / \mathrm{Zr}$ catalyst characterizes the mutual conversion of adsorbed oxygen and bulk oxygen on the surface. As shown in the figure, the oxygen storage capacity of $\mathrm{La}_{0.05} \mathrm{Ce}_{0.65} \mathrm{Zr}_{0.3} \mathrm{O}_{2}$ is $448 \mu \mathrm{mol} / \mathrm{g}$, which is $7.7 \%$ higher than that

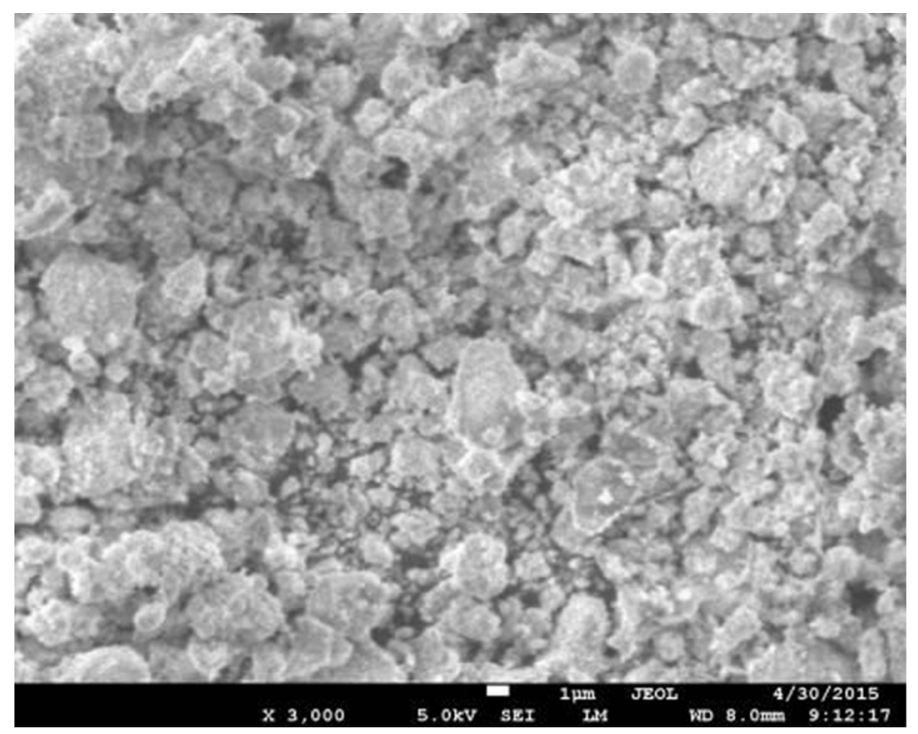

(a) Fresh State

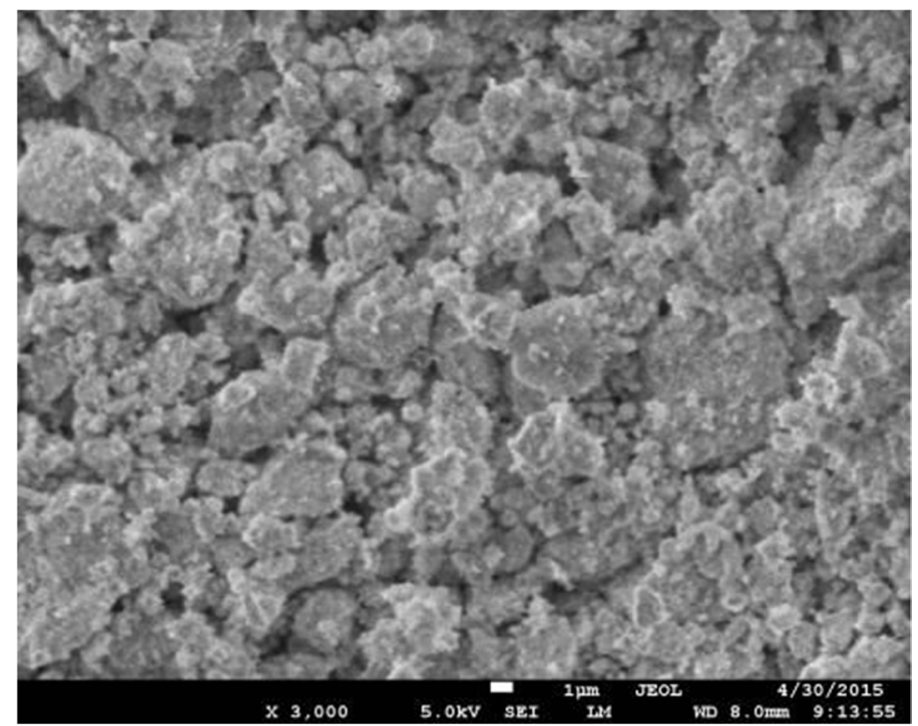

(b) Heat Aging

Figure 2. SEM Image of the LCZ. 
of pure $\mathrm{Ce} / \mathrm{Zr}$ composite. The addition of $\mathrm{La}$ increases the specific surface area of the composite and enhances the catalyst powder contacting with $\mathrm{O}_{2}$ and surface adsorption (Gao \& Dai, 2011). It also makes the Ce/Zr component of the surface more dispersed, increasing the number of active sites, and the Ce/Zr composite phase is cubic phase, and the OSC ability is stronger (Zhao et al., 2007) (Zhan et al., 2007). On the other hand, it is known from XRD analysis that after the partial substitution of $\mathrm{Ce}$ for $\mathrm{La}$, La penetrates into the crystal lattice of yttrium oxide and zirconia. Due to the small atomic radius of $\mathrm{La}$, non-stoichiometric structural defects are formed, resulting in more oxygen vacancies. Lattice structure defects and oxygen vacancies facilitate the migration and diffusion of oxygen ions, which promotes the conversion of adsorbed oxygen and bulk oxygen on the catalyst surface. Therefore, the addition of La enhances the mobility of the catalyst lattice oxygen, and indirectly proves that the surface oxygen vacancies of the catalyst increase after the addition of La.

\subsection{Heat Aging Resistance}

As shown in Table 4, in the high exhaust temperature state of the diesel engine, the instantaneous temperature rise can reach nearly $1000^{\circ} \mathrm{C}$. In this environment, the catalyst is prone to heat aging, the physical and chemical properties are reduced, and some or even completely lose the catalytic activity. The aging of the catalyst is generally reflected in two aspects: the surface morphology change and the phase change of the powder particles. Thermal aging causes high temperature sintering of the catalyst surface, resulting in a decrease in specific surface area, affecting interfacial contact between the reactants and the catalyst, and also reducing the surface activity of the catalyst. For the Ce/Zr composite, the high temperature causes the surface active component to sinter, resulting in a decrease in its oxygen storage capacity. In addition, the loss of activity at high temperatures may also be due to the "deterioration" of the catalyst and the transformation of its crystal phase structure. Changes in the above conditions

Table 3. Changes in oxygen storage in fresh state before and after la modification.

\begin{tabular}{ccccc}
\hline Catalyst & Parameter & $\begin{array}{c}\text { Specific surface } \\
\text { area } \mathrm{m}^{2} / \mathrm{g}\end{array}$ & $\begin{array}{c}\text { Specific surface } \\
\text { area increase } \\
\text { ratio } \%\end{array}$ & $\begin{array}{c}\text { Oxygen storage } \\
\left(200^{\circ} \mathrm{C}\right)\end{array}$ \\
\hline $\mathrm{Ce}_{0.7} \mathrm{Zr}_{0.3} \mathrm{O}_{2}$ & 50.89 & 0 & 416 & $\begin{array}{c}\text { Oxygen } \\
\text { storage rate } \\
\text { change rate } \%\end{array}$ \\
$\mathrm{La}_{0.05} \mathrm{Ce}_{0.65} \mathrm{Zr}_{0.3} \mathrm{O}_{2}$ & 67.37 & 32.4 & 448 & 0 \\
\hline
\end{tabular}

Table 4. Thermal aging test parameters before and after La modification.

\begin{tabular}{ccccccc}
\hline & Parameter & $\begin{array}{c}\text { Heat aging } \\
\text { temperature } \\
\text { Catalyst }\end{array}$ & $\begin{array}{c}\text { Specific } \\
\text { surface } \\
\text { area } \mathrm{m}^{2} / \mathrm{g}\end{array}$ & $\begin{array}{c}\text { Specific } \\
\text { surface } \\
\text { reduction rate } \\
\text { after aging } \%\end{array}$ & $\begin{array}{c}\text { Oxygen } \\
\text { storage } \\
\left(200^{\circ} \mathrm{C}\right) \\
10^{-6} \mathrm{~mol} / \mathrm{g}\end{array}$ & $\begin{array}{c}\text { Rate of oxygen } \\
\text { storage } \\
\text { reduction after } \\
\text { aging } \%\end{array}$ \\
\hline \multicolumn{2}{c}{$\mathrm{Ce}_{0.7} \mathrm{Zr}_{0.3} \mathrm{O}_{2}$} & $1000(4 \mathrm{~h})$ & 17.91 & 64.9 & 254 & 38.9 \\
$\mathrm{La}_{0.05} \mathrm{Ce}_{0.65} \mathrm{Zr}_{0.3} \mathrm{O}_{2}$ & $1000(4 \mathrm{~h})$ & 25.07 & 62.8 & 335 & 25.2 \\
\hline
\end{tabular}


will greatly affect the performance of the catalyst. In some literatures, the $\mathrm{Ce} / \mathrm{Zr}$ complex oxidation can be used in a high temperature environment of $1000^{\circ} \mathrm{C}$ on the basis of ensuring high oxygen storage performance. Therefore, the heat aging test at $1000^{\circ} \mathrm{C}$ is mainly to determine the modified Resistance of Ce/Zr composites to high temperature sintering.

It can be seen from the table data that in the high temperature environment, the surface of the catalyst is sintered to different degrees, so that the specific surface area is decreased and the oxygen storage capacity is lowered. The specific surface area of $\mathrm{La}_{0.05} \mathrm{Ce}_{0.65} \mathrm{Zr}_{0.3} \mathrm{O}_{2}$ decreased from $67.37 \mathrm{~m}^{2} / \mathrm{g}$ in fresh to 25.07 $\mathrm{m}^{2} / \mathrm{g}$, and the specific surface area reduction rate was $62.8 \%$. OSC decreased to $335 \mu \mathrm{mol} / \mathrm{g}$, and the reduction rate was $25.2 \%$, while pure $\mathrm{Ce}_{0.7} \mathrm{Zr}_{0.3} \mathrm{O}_{2}$ was reduced from $50.89 \mathrm{~m}^{2} / \mathrm{g}$ at fresh to $17.91 \mathrm{~m}^{2} / \mathrm{g}$, the specific surface area reduction rate was $64.9 \%$, and the OSC was reduced to $254 \mu \mathrm{mol} / \mathrm{g}$, and the reduction rate was $41.7 \%$. The specific surface areas of the two catalyst powders decreased by a large margin, while the degree of oxygen storage decreased by a large margin. Before the high temperature sintering, the surface of the catalyst will first undergo the process of crystal growth. After the crystal grows to a certain extent, the crystals will contact each other to produce sintering adhesion. CeZrO has a small surface area after aging, and its crystal growth is coarse, and its oxygen storage capacity decreases significantly, indicating that the surface sintering of $\mathrm{CeZrO}$ is more serious after high temperature aging. Although the specific surface area of $\mathrm{LaCeZrO}$ is also decreased, the degree of decline is lower than that of $\mathrm{CeZrO}$, and its oxygen storage capacity is only reduced by $25.2 \%$, indicating that although the crystal of LaCeZrO grows, its coarseness is lower than that of Ce$\mathrm{ZrO}$, which makes $\mathrm{LaCeZrO}$. The surface sintering condition is improved. Therefore, the addition of La slows down the growth of the crystals to a certain extent, improves the high-temperature sintering of the catalyst, and reduces the influence of the high-temperature environment on the oxygen storage capacity. Therefore, it can be concluded that when La is substituted for $5 \%$ by mass of Ce, the degree of surface sintering of $\mathrm{Ce} / \mathrm{Zr}$ composite at high temperature can be suppressed, and the heat aging resistance is improved.

\subsection{Adsorption and Catalytic Performance}

1) Adsorption Test

In the heterogeneous catalytic reaction, the gaseous reactant first completes the adsorption on the surface of the catalyst, which is a prerequisite for the initiation of the catalytic reaction. The adsorption of the gaseous reactant on the surface of the catalyst can be divided into physical adsorption and chemical adsorption. Activate adsorption state formed on the surface of the catalyst can reduce the activation energy of the reaction process, thereby facilitating the reaction.

Figure 3 shows the concentration curve of NO in the NO adsorption experiment before and after La modification. The simulated sample gas is $1000 \mathrm{ppm} \mathrm{NO}+$ $\mathrm{He}$, and the decrease of nitric oxide concentration is its adsorption amount on the surface of the catalyst powder. We can measure the NO adsorption performance 


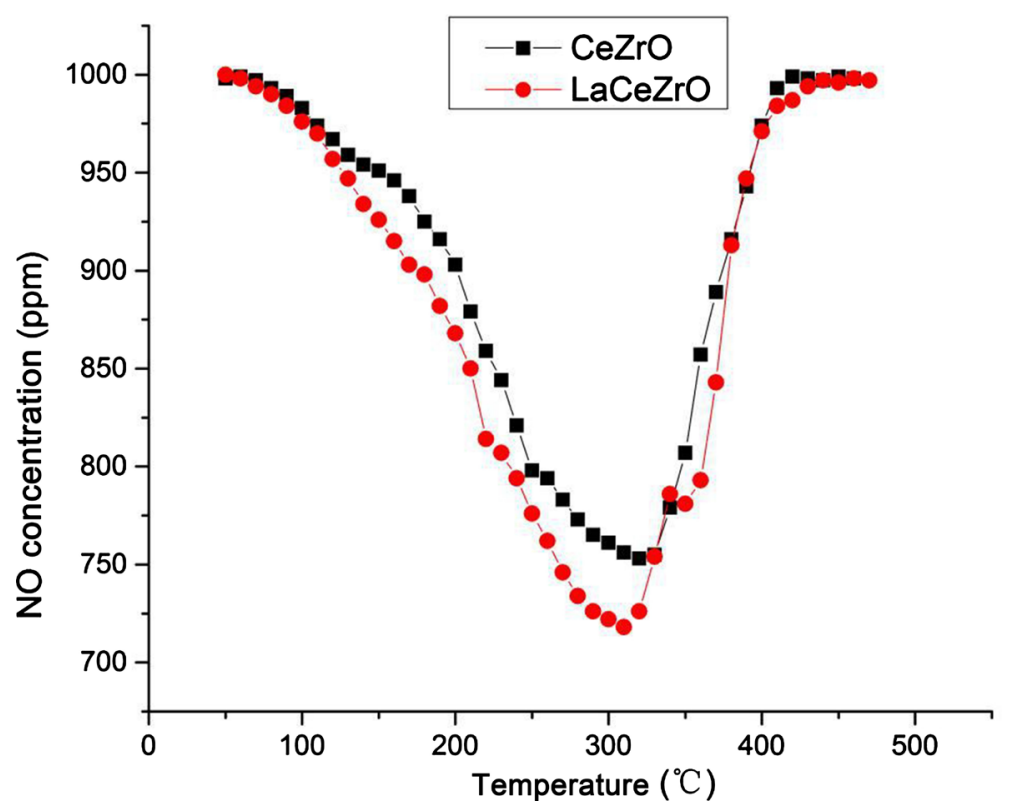

Figure 3. Comparison of NO adsorption curves of catalysts before and after La modification.

by the adsorption rate of $\mathrm{NO}$ at different temperatures.

$$
[\mathrm{NO}]_{\text {Adsorption rate }}=1-[\mathrm{NO}]_{\text {measuring }} / 1000
$$

$[\mathrm{NO}]_{\text {measuring }}$ is the measured value of NO concentration at the exit of the program temperature control platform;

From the concentration curve of the figure, we can see that there are two obvious concave areas in the concentration curve, indicating that the adsorption stage is divided into two processes: low temperature zone and high temperature zone. The adsorption in the low temperature zone is generally physical adsorption, and the adsorption rate and adsorption amount are generally small, mainly due to the adsorption of surface diffusion and viscous action. The adsorption curve of LaCeZrO has a small concave at $100^{\circ} \mathrm{C}-150^{\circ} \mathrm{C}$, and its degree of undercut is higher than that of $\mathrm{CeZrO}$, mainly due to the larger specific surface area and surface structure of LaCeZrO, which increases the powder and NO. Contact area, enhanced physical adsorption of LaCeZrO.

With constant heating, the catalyst is activated by thermal energy to start the chemisorption process. At this stage, the adsorption rate is faster, the adsorption amount is relatively large, and the driving force is the intermolecular force, so that the reactant is adsorbed on the active site. The adsorption curve of $\mathrm{LaCeZrO}$ has a larger slope in the range of $150^{\circ} \mathrm{C}-250^{\circ} \mathrm{C}$. Compared with the adsorption curve of $\mathrm{CeZrO}$, the adsorption rate of $\mathrm{NO}$ is obvious, indicating that the adsorption rate of $\mathrm{NO}$ is faster, and the adsorption amount of $\mathrm{NO}$ at each temperature point is also increased. The adsorption peak decreased obviously, the highest peak NO adsorption rate was $28.3 \%$, and the adsorption front curve slightly moved forward, indicating that the $\mathrm{NO}$ adsorption rate and adsorption capacity of LaCeZrO in the chemisorption stage were improved. 
After replacing the Ce with the La moiety, due to the larger atomic radius of $\mathrm{La}$ and the potential balance after the infiltration of $\mathrm{La}^{3+}$, more structural defects are formed in the formed composite phase, forming oxygen vacancies. Therefore, the number of oxygen vacancies on the surface of LaCeZrO is large, which can promote the surface adsorption of NO. The experimental results are also consistent with the research conclusions of Zhao Zhen et al. (Gao \& Dai, 2011). In addition, there are also literatures indicates that La can reduce the oxygen bond energy and enhance the decomposition and adsorption capacity of NO.

After the adsorption process reached its peak, the NO concentration did not quickly return to $1000 \mathrm{ppm}$, indicating that a part of $\mathrm{NO}$ was converted into other substances during the adsorption process. It may be that nitric oxide is directly separated from the active site, resulting in $\mathrm{N}_{2}$ or $\mathrm{N}_{2} \mathrm{O}$, and this also is the result of $\mathrm{NO}$ activation.

In summary, the integral of the adsorption curve increases, that is, the NO adsorption amount increases throughout the adsorption phase, and it can be inferred that the addition of La increases the $\mathrm{NO}$ adsorption capacity of CeZrO.

2) Catalytic Performance Test

Figure 4 shows the results of the temperature rise reaction of catalytic LaCe$\mathrm{ZrO}$ catalytic oxidation of PM and reduction of NO. From the curve of the concentration of each component in the figure, it can be seen that the increase of $\mathrm{CO}_{2}$ concentration and the decrease of $\mathrm{NO}$ concentration are within the same temperature range $\left(200^{\circ} \mathrm{C}-600^{\circ} \mathrm{C}\right)$, and the change of the concentration curve is more matched, which indicates that the oxidation energy of PM and the activation energy of NO reduction are relatively close, and there is a correlation between

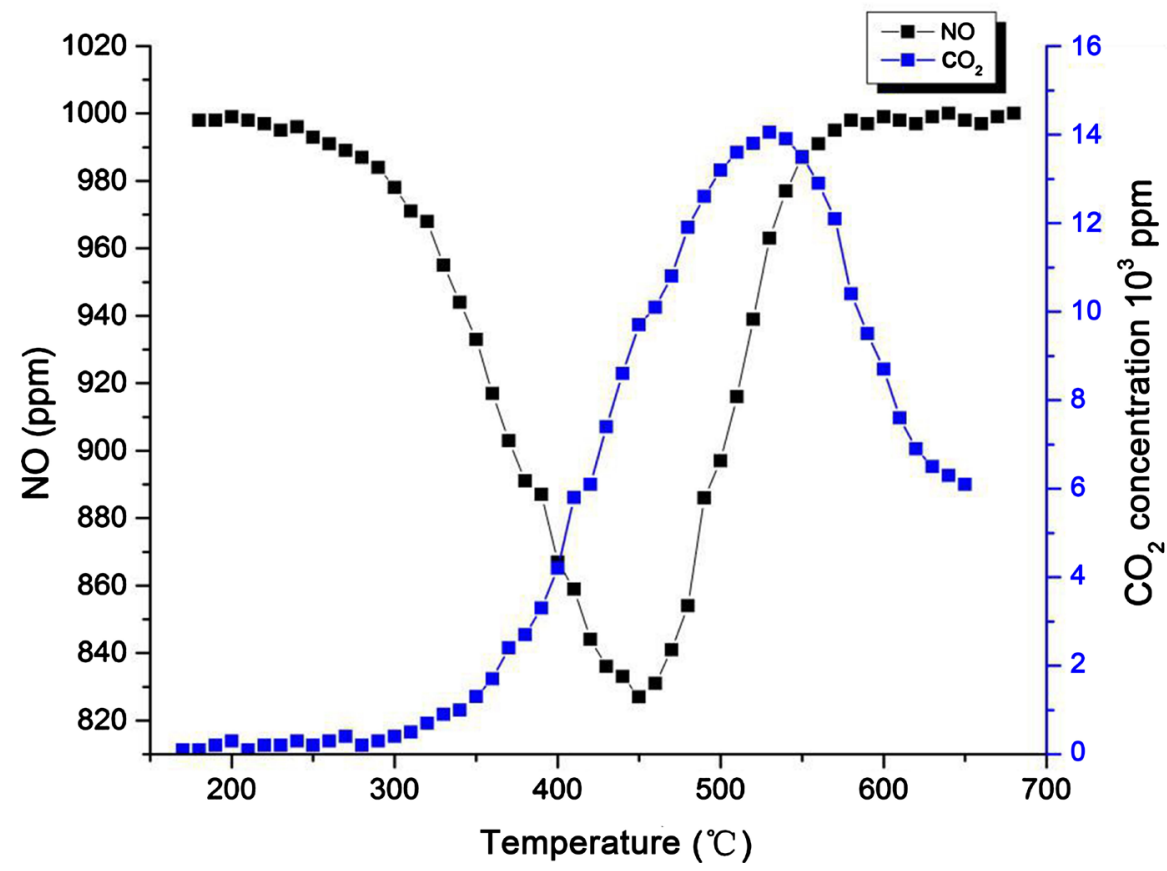

Figure 4. TPR Curve under $\mathrm{NO}$ and $\mathrm{O}_{2}$ atmosphere. 
the two. Therefore, the PM and other components in the diesel flue gas can be used as a reducing agent to catalyze the removal of NOx.

The following is the reaction process of the catalytic reaction:

$$
\begin{gathered}
\mathrm{C}+\mathrm{O}_{2}=\mathrm{CO}_{2} \\
\mathrm{C}+2 \mathrm{NO}=\mathrm{N}_{2}+\mathrm{CO}_{2} \\
2 \mathrm{C}+2 \mathrm{NO}_{2}=\mathrm{N}_{2}+2 \mathrm{CO}_{2}
\end{gathered}
$$

The method for determining the combustion onset temperature and the maximum activation temperature of $\mathrm{PM}$ has been described above. The $\mathrm{CO}_{2}$ generation rate is calculated as follows: in the simulated atmosphere, the oxidizing gas is only $\mathrm{NO}$ and $\mathrm{O}_{2}$ or $\mathrm{NO}, \mathrm{NO}_{2}$ and $\mathrm{O}_{2}$. If the stoichiometric ratio can be completely reacted, the highest concentration of $\mathrm{CO}_{2}$ in the exhaust gas is $2.05 \%$ and $2.06 \%$, respectively. The $\mathrm{CO}_{2}$ concentration is divided by the corresponding highest concentration value to obtain the $\mathrm{CO}_{2}$ production rate.

$$
\begin{gathered}
{\left[\mathrm{CO}_{2}\right]_{\text {generation rate }}=\left[\mathrm{CO}_{2}\right]_{\text {measuring }} / 2.05 \%} \\
{[\mathrm{NOx}]_{\text {reduction rate }}=1-[\mathrm{NOx}]_{\text {measuring }} /[\mathrm{NOx}]_{\text {simulation }}}
\end{gathered}
$$

$\left[\mathrm{CO}_{2}\right]_{\text {measuring }}$ is the measured value of the $\mathrm{CO}_{2}$ concentration at the exit of the programmed temperature control platform;

$[\mathrm{NO}]_{\text {measuring }}$ is the measured value of the NO concentration at the exit of the programmed temperature control platform;

$[\mathrm{NO}]_{\text {simulation }}$ simulates $\mathrm{NO}$ content in gas.

In the $\mathrm{NO}$ and $\mathrm{O}_{2}$ atmosphere, the light-off temperature of PM is about $335^{\circ} \mathrm{C}$, which is $155^{\circ} \mathrm{C}$ lower than the light-off temperature of non-catalytic combustion, and the highest oxidation catalytic activity temperature is about $530^{\circ} \mathrm{C}$ (the interval between the values is large, so it is the inter-cell range value) is lower than the light-off temperature and the highest activity temperature of CeZrO (Liu, 2009) (Fornasiero et al., 1995), and the maximum production rate of $\mathrm{CO}_{2}$ is $68.5 \%$; the maximum reduction rate of $\mathrm{NO}$ is $17.3 \%$. After the temperature of the program rises above $600^{\circ} \mathrm{C}$, the $\mathrm{CO}_{2}$ concentration decreases slightly and tends to be stable. It may be the superposition of catalytic oxidation activity and self-oxidation enhancement. The concentration of NO in the interval of $550^{\circ} \mathrm{C}-600^{\circ} \mathrm{C}$ also returns to the benchmark and remains stable, indicating that the rate of $\mathrm{CO}_{2}$ concentration declines at a temperature above $600^{\circ} \mathrm{C}$, but it may only be due to the high temperature increasing the oxidation rate of $\mathrm{PM}$, and the oxidation catalytic ability of the catalyst is inhibited. The temperature range of the catalyst activity test is in the range of $650^{\circ} \mathrm{C}$ or less.

Figure 5 shows TPR curves under $\mathrm{NO}, \mathrm{NO}_{2}$ and $\mathrm{O}_{2}$. The light-off temperature of $\mathrm{PM}$ is about $320^{\circ} \mathrm{C}$, which is $170^{\circ} \mathrm{C}$ lower than the light-off temperature of non-catalytic combustion, while the ignition temperature of $\mathrm{PM}$ of $\mathrm{Ce}_{0.7} \mathrm{Zr}_{0.3} \mathrm{O}_{2}$ (Zhao et al., 2007) is $370^{\circ} \mathrm{C}$, and $\mathrm{LaCeZrO}$ is about $50^{\circ} \mathrm{C}$ lower than it. The highest oxidation activity temperature of $\mathrm{LaCeZrO}$ to $\mathrm{PM}$ is about $510^{\circ} \mathrm{C}$, which is about $20^{\circ} \mathrm{C}$ lower than the highest oxidation activity temperature of pure 


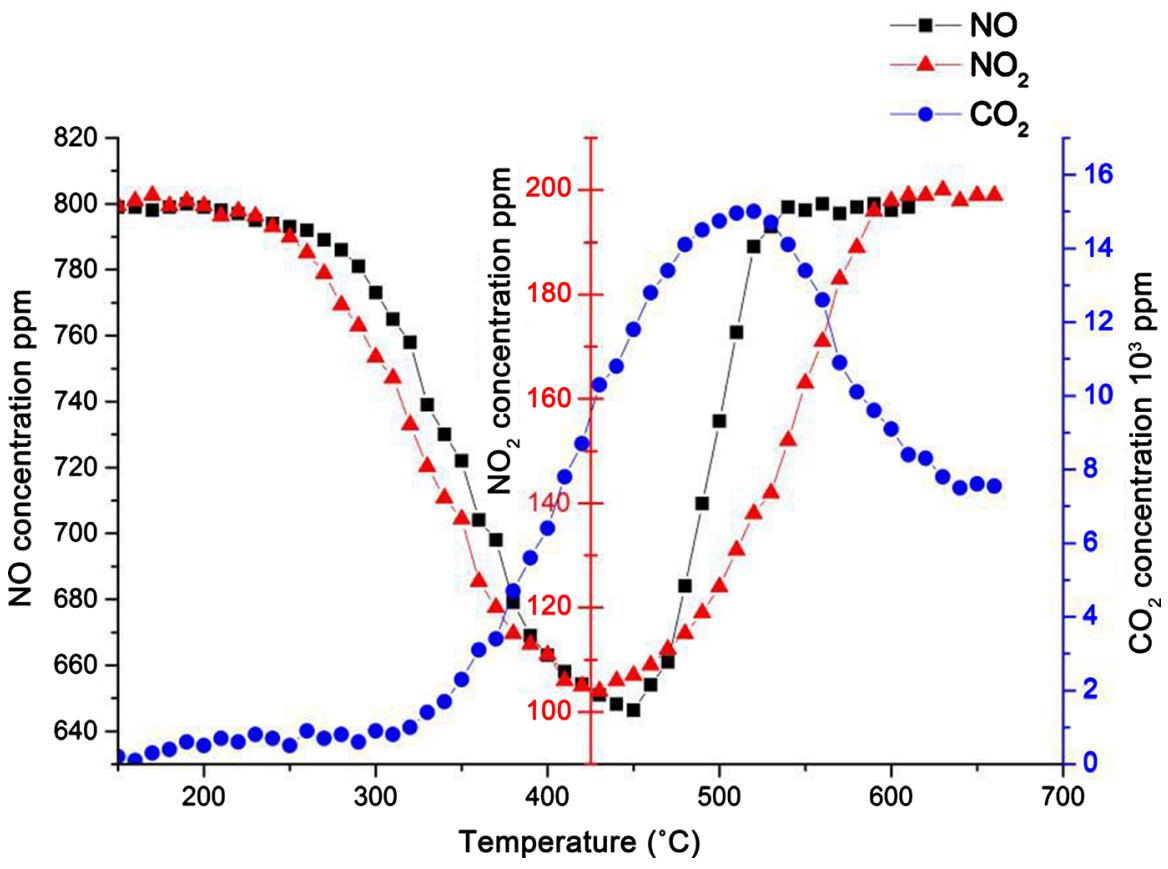

Figure 5. TPR Curves under $\mathrm{NO}, \mathrm{NO}_{2}$ and $\mathrm{O}_{2}$

cerium-zirconium composite; the maximum formation rate of $\mathrm{CO}_{2}$ is $72.8 \%$, which are nearly 9 more than $\mathrm{Ce}_{0.7} \mathrm{Zr}_{0.3} \mathrm{O}_{2}$. The percentage of $\mathrm{NO}$ is $19.2 \%$, which is $2.4 \%$ higher than that of $\mathrm{Ce}_{0.7} \mathrm{Zr}_{0.3} \mathrm{O}_{2}$; the reduction rate of $\mathrm{NO}_{2}$ is up to $48 \%$ at $460^{\circ} \mathrm{C}$; the reaction temperature range of $\mathrm{NO}_{2}$ is wider than that of $\mathrm{NO}$, indicating that $\mathrm{NO}_{2}$ has better oxidation and is easier to be reduced. The NOx concentration reduction curve and the $\mathrm{CO}_{2}$ concentration growth curve are approximately matched.

By comparing Figure 4 with Figure 5, it can be concluded that due to the presence of $\mathrm{NO}_{2}$, the $\mathrm{CO}_{2}$ generation curve moves forward, the peak-to-peak value increases, the reduction temperature range of $\mathrm{NO}$ widens, and the reduction rate also increases, that is, $\mathrm{NO}_{2}$ existence enhances $\mathrm{PM}$ oxidation and $\mathrm{NO}$ reduction.

It has been reported that the decomposition of $\mathrm{NO}$ is that $\mathrm{NO}$ is first adsorbed on the active site on the surface of the catalyst, and the NO bond energy is reduced, and then the $\mathrm{NO}$ is combined with the adjacent active sites to form $\mathrm{NO}$ $[\mathrm{N}]$ and $[\mathrm{O}]$ in the adsorption activated state. Then two $[\mathrm{N}]$ generate $\mathrm{N}_{2},[\mathrm{O}]$ and [CO] generate $\mathrm{CO}_{2}$. Therefore, increasing the number of active sites can improve the catalytic performance of the powder material. In the previous section, we have explained that the activation and decomposition of $\mathrm{NO}$ is related to the migration of lattice oxygen. The infiltration of La increases the oxygen vacancies of the complex, and the oxide complex system of the niobium has a special oxygen vacancy aggregation, which enhances the activity of lattice oxygen. And migration ability promotes the activation and decomposition of NO, which is basically consistent with the experimental results.

In summary, the addition of La is beneficial to the activation and decomposi- 
tion of NO, effectively reducing the activation energy of the reaction, increasing the oxygen vacancies, improving the exchange of lattice oxygen and adsorbed oxygen on the catalyst surface, and enhancing the Ce/ $\mathrm{Zr}$ complex to NO catalytic removal capacity.

\section{Conclusion}

In this paper, the partial replacement of Ce by $\mathrm{La}$ is carried out to modify the $\mathrm{Ce} / \mathrm{Zr}$ composite oxide. The mass fraction of $\mathrm{La}_{2} \mathrm{O}_{3}$ in the prepared $\mathrm{La} / \mathrm{Ce} / \mathrm{Zr}$ composite oxide was $5 \%$, and the physicochemical properties of $\mathrm{La} / \mathrm{Ce} / \mathrm{Zr}$ composite oxide powder were analyzed by ICP, OSC, SEM and TPR techniques.

It was found that La can refine crystals and inhibit crystal growth, so that the powder obtains higher specific surface area and smaller particle size distribution, and the inhibition at high temperature reduces the sintering of cerium-zirconium and improves the catalyst heat aging resistance; the addition of La can enhance surface lattice oxygen migration and oxygen storage capacity and it can enhance NO adsorption capacity of cerium zirconium, and improve catalyst catalytic activity; PM light-off temperature and maximum activate temperature is lowered, and the reduction rate of No is $19.2 \%$.

\section{Conflicts of Interest}

The author declares no conflicts of interest regarding the publication of this paper.

\section{References}

Dong, H., \& Shuai, S. (2007). The Latest Development and Development Trend of Diesel Exhaust after Treatment Technology. Small Internal Combustion Engines and Motorcycles, 36, 87-92.

Fornasiero, P., Di Monte, R., Rao, G. R. et al. (1995). Rh-Loaded $\mathrm{CeO}_{2}-\mathrm{ZrO}_{2}$ Solid-Solution as Highly Efficient Oxygen Exchangers: Dependence of the Reduction Behavior and the Oxygen Storage Capacity on the Structural-Properties. Journal of Catalysis, 151, 168-177. https://doi.org/10.1006/jcat.1995.1019

Gao, S., Qu, J., Lu, C. et al. (2001). Development Status of Foreign Diesel Engine Emission Regulations and Emission Control Technologies. Journal of Shandong Institute of Engineering, 15, 38-42.

Gao, Z., \& Dai, H. (2011). Practical Catalysis. Beijing: Chemical Industry Press.

Li, D., Zhang, H., Zhang, H., Guo, Q., \& Cao, M. (2006). Research and Application Progress of Perovskite Type Composite Oxide. Materials Review, No. S1, 296-299.

Liu J. (2009). Nanocatalysts in Diesel Vehicle Exhaust Gas Purification. Summary of the 5th National Conference on Environmental Chemistry, Environmental Chemistry Committee of China Chemical Society, Chinese Chemical Society Environmental Chemistry Committee, Chinese Chemical Society, 2.

Tsyganok, A. I., Inaba, M., Tsunoda, T. et al. (2004). Combined Partial Oxidation and Dry Reforming of Methane to Synthesis GAI over Noble Metals Supported on Mg-Al Mixed Oxide. Applied Catalysis A: General, 275, 149-155.

https://doi.org/10.1016/j.apcata.2004.07.030 
Wang, W., Mao, D., Wu, G., \& Guo, X. (2008). Preparation and Application of Copper/Zirconium Oxide Catalysts. Chemical Industry Progress, 27, 47-52.

Wang, Z., \& Shi, Q. (2006). Preparation and Characterization of Rare Earth Modified Cerium Zirconium Solid Solution. Journal of Catalysis, 23, 12-16.

$\mathrm{Xu}$, Z. et al. (2009). Development of Diesel Particulate Filter for Marine Diesel Engine: Characteristics of PM Collection in Electrostatic-Cyclone DPF. Marine Engineering 44, 304-309. https://doi.org/10.5988/jime.44.304

Yoshida, D., Hatanaka, Y., \& Kifune, H. (2006). Development of Marine Diesel Particulate Filter by Means of High Frequency Induction Heating. Marine Engineering, 41, 889-894.

Zhan, W., Cai, G., Xiao, Y. et al. (2007). Relationship between Oxygen Storage Performance and Structure of $\mathrm{Ce}_{\mathrm{x}} \mathrm{Zr}_{1-\mathrm{x}} \mathrm{O}_{2}$ Solid Solution. Spectroscopy and Spectral Analysis, 27, 2266-2269.

Zhang, G., Han, L., Zhao, Z., \& Liu, J. (2008). Research Progress of Four-Way Catalytic Purification Technology for Diesel Vehicle Exhaust Gas. Journal of Catalysis, 22, 62-66.

Zhao, M., Wang, J., \& Shen, M. (2007). Effect of Specific Surface Area and Bulk Structure of Cerium-Zirconium Solid Solution on Oxygen Storage and Storage Performance. In Proceedings of the 4th National Conference on Rare Earth Catalysis (pp. 82-91). Wuxi. 